\title{
A SAÚDE ENTRE O PÚBLICO E O PRIVADO: O DESAFIO DA ALOCAÇÃO SOCIAL DOS RECURSOS SANITÁRIOS ESCASSOS Osmir Antonio Globekner, Juruá, São Paulo, 2011
}

André Bastos Lopes Ferreira*

A obra em análise trata das diversas faces de um dilema que assoma o atual cenário republicano brasileiro, vicissitude essa que erige dos compromissos estatais assumidos diante da promulgação da Constituição de 1988 e que agora parece distante de qualquer consenso possivelmente pacificador de sua compreensão.

O fenômeno supra aludido é o enigma da alocação coligada dos recursos públicos e privados com a finalidade de promoção do direito à saúde, tema cuja multidisciplinariedade está implícita na denominação (direito - saúde), mas que fatidicamente necessita de uma abordagem mais ampla ainda. O autor, ao reconhecer essa dificuldade, se propõe a apreciar a questão conforme o método de análise "complexo", contabilizando as perspectivas econômicas, políticas, sociais, sanitárias, éticas e jurídicas que necessariamente influem no processo deliberativo, tanto social (stricto sensu) quanto governamental (políticas públicas).

Entre os principais pressupostos teóricos que possibilitam a análise do tema, é necessário conceituar o direito à saúde e as garantias que nele estão inseridas, bem como as diferentes modalidades de direitos fundamentais e a classificação da saúde entre elas.

Destarte, a saúde é tida como conceito negativo, em uma perspectiva de direito fundamental de primeira geração, consistindo em uma proteção da integridade física do cidadão contra turbações ilícitas e ilegítimas do Estado ou de terceiros. Nas dimensões de segunda e terceira geração de garantias sociais, assume as características de valoração positiva, como atos concretos de promoção ao bem-estar físico e psíquico da sociedade, assumindo como responsabilidade do Estado a garantia de fornecer condições salubres que proporcionem vida digna e bem-estar, em caráter universal.

(*) Estudante da Faculdade de Direito da Universidade de São Paulo; Pesquisador do Núcleo de Pesquisa em Direito Sanitário da Universidade de São Paulo (NAP-DISA/USP ). E-mail: andrebastosferreira@hotmail.com.

Texto recebido em 10.09.2012. 
A Constituição da República assim dispõe, com a finalidade de assegurar tal direito à saúde, entre outros: "Art. $6^{\circ}$ São direitos sociais a educação, a saúde, a alimentação, o trabalho, a moradia, o lazer, a segurança, a previdência social, a proteção à maternidade e à infância, a assistência aos desamparados, na forma desta Constituição".

Ocorre que, apesar das inúmeras obrigações estatais compromissadas pela constituição, é necessário interpretar as disposições normativas também segundo as pretensões do poder constituinte e das possibilidades do orçamento público. Nesse diapasão, a hermenêutica teleológica nos permite classificar o direito à saúde, conforme o sistema adotado por Manoel Gonçalves Ferreira Filho(1), como uma norma de caráter "não autoexecutável", de ordem programática. Ou seja, essa norma exige, em conformidade com os padrões paradigmáticos dos demais direitos sociais, atos concretos, em forma de dispêndio público, para a sua efetivação.

Essa exigência torna ínsita a compreensão de agentes públicos e beneficiários dos direitos mencionados de que, embora a norma tenha eficácia imediata, conforme retificado pelo texto, ela estabelece garantias a serem paulatinamente integradas à disponibilidade social, sendo impossível seu fornecimento imediato. Por esse motivo é que se atribui ao século XX o relevante mérito de formalização legal dos direitos fundamentais (em Estados democráticos de direito), restando o desafio de implementá-los ao século XXI.

Apesar da notável precisão científica, crítica e conceitual do texto em objeto, parece que essa abordagem estritamente jurídica-constitucional não foi incisivamente enfatizada, com a mesma prioridade, por exemplo, que os conceitos econômicos, também de precípua relevância ao tema. Essa perspectiva jurídico-normativa tem suas consequências no âmbito financeiro, como será explicado adiante.

A saúde entre o público e o privado tem entre seus méritos o reconhecimento bastante razoável de que "A realização de quaisquer direitos pressupõe a alocação de recursos materiais necessários, ou, em outra perspectiva, a alocação de recursos determina quais direitos serão implementados e quais deixarão de sê-lo". Nesse sentido é perceptível uma relação dialética entre forças sociais que exigem o cumprimento de seus direitos e a força manifestamente escassa que está disponível para satisfazê-los, o orçamento público. No limite, é possível estimar que as exigências sociais são "infinitas", enquanto o orçamento é "finito", tendo por corolário um sistema que, interpretado de forma incoerente com as finalidades jurídicas que o estabeleceu, gera um paradoxo cujo resultado seria invariavelmente a catastrófica bancarrota do Estado.

Esse ponto, também abordado na obra, porém, não com grande enfoque, repercute a tendência social em larga expansão de "judicialização da saúde",

(1) FERREIRA FILHO, Manoel Gonçalves. Curso de direito constitucional. 35. ed. São Paulo: Saraiva, 2009. p. 390. 
em que se demanda do Poder Judiciário o provimento jurisdicional positivo de coagir o poder estatal a fornecer tratamentos médicos a um determinado indivíduo ou grupo. Tal comportamento conota certa maturidade política e jurídica da sociedade, que se percebe como titular de direitos diante do Estado, e pretende exigir seu cumprimento. No entanto, caso levado a cabo, pode gerar insuperáveis déficits orçamentários, além de flagrante ruptura com o pacto de tripartição de poderes, na medida em que o judiciário determina a alocação de determinados recursos orçamentários sem prévia previsão legal para tal.

As eleições de representantes para ocupação de cargos do Poder Executivo são atribuições de competência, delegando poderes aos eleitos para, de forma bastante simplificada e restrita, exercer a função soberana de administrar os recursos do estado. O Espírito das Leis, doutrina "clássica" de Montesquieu, incorporada pelo atual regime democrático-constitucional, prescreve que as funções estatais básicas são "o poder legislativo, o poder executivo das coisas que emendem do direito das gentes e o poder executivo daquelas que dependem do direito civil(2)". Atualmente, nomeamos os três "poderes", assim descritos, de: Legislativo, Executivo e Judiciário, respectivamente, cabendo a cada um distintamente exercer sua função, com interferência limitada dos demais.

Mesmo com aplicabilidade mais restrita à atualidade, o mecanismo tripartite é expressamente adotado na constituição da república, como método de freios e contrapesos (checks and balances) entre os poderes estatais. A intervenção judiciária que se exceda a prover o mínimo existencial ou medidas que possam ser universalizadas a todos os cidadãos caracteriza evidente abuso inescusável. Essa irresponsabilidade pode prejudicar milhares de cidadãos, concedendo prestações em flagrante desproporção com os princípios constitucionais de fiscalização contábil, a que estão sujeitos os órgãos do Poder Executivo (legalidade, legitimidade e economicidade, Art. 70 da Constituição Federal(3)).

A matéria da alocação per se de recursos financeiros, sejam públicos, sejam privados, foi largamente abrangida pela obra ora em análise. Esse aspecto, prioritariamente econômico da abordagem, demonstrou extensa pesquisa e embasamento teórico em diversos autores de renome e notório

(2) MONTESQUIEU, Charles Luis de Secondat. O Espírito das leis. Disponível em: <www.file:////Lenin/ RedeLocal/Equipe/Michele/MONTESQUIEU-OEspíritodasLeis2.txt>. Acesso em: 29. out. 2012.

(3) Art. 70. A fiscalização contábil, financeira, orçamentária, operacional e patrimonial da União e das entidades da administração direta e indireta, quanto à legalidade, legitimidade, economicidade, aplicação das subvenções e renúncia de receitas, será exercida pelo Congresso Nacional, mediante controle externo, e pelo sistema de controle interno de cada Poder. Parágrafo único. Prestará contas qualquer pessoa física ou jurídica, pública ou privada, que utilize, arrecade, guarde, gerencie ou administre dinheiros, bens e valores públicos ou pelos quais a União responda, ou que, em nome desta, assuma obrigações de natureza pecuniária. (Redação dada pela Emenda Constitucional $n^{\circ} 19$, de 1998). BRASIL. Constituição da República Federativa do Brasil de 1988. Disponível em: <http:// www.planalto.gov.br/ccivil_03/constituicao/ConstituicaoCompilado.htm>. Acesso em: 17 out. 2012. 
conhecimento de macro e microfinanças e que, de forma didática, são simplificadamente subdivididos entre teóricos "liberais" e "sociais". Ambas as escolas, embora com incongruências epistemológicas e metodológicas, analisam o fenômeno socioeconômico com a finalidade de propor modelos que permitam a melhor eficiência financeira, visando à equidade, à eficiência e ao bem-estar universal.

Para o autor, "no âmbito do pensamento liberal, a equidade está fundada na igualdade das condições iniciais necessárias à preservação da liberdade individual e na promoção de coesão social", enquanto, para o pensamento social, "a equidade está fundada na promoção ativa da distribuição e redistribuição de bens socialmente produzidos, visando obter uma igualdade substantiva, de resultados e não somente de meios". É perceptível, nessa linha de raciocínio, que há certa relação coerentemente antagônica entre a igualdade formal e material, pois ao tratar de forma distinta entes sociais, diferenciáveis por critérios diversos, necessariamente se abdica da estrita igualdade formal, mesmo que com intuito de promover o bem comum.

Nesse espectro de compreensão da realidade econômica e seus agentes propulsores, há grande limitação teórica conducente ao próprio significado de "justiça", em termos de alocação e distribuição dos recursos coletivos, fundamentalmente sendo o objetivo de ambas correntes ideológicas, mas sem consenso quanto a sua conceituação.

Para Tércio Ferraz Junior, o conceito de "justiça" em seu aspecto formal é um "valor ético-social de proporcionalidade em conformidade com o qual, em situações bilaterais normativamente reguladas, exige-se a atribuição a alguém daquilo que lhe é devido" e em seu aspecto material "a determinação daquilo que é devido a cada um"(4). De certa forma esse conceito é uma racionalização do que intuitivamente se entende por "justo", restando à prática consuetudinária, através de um cotejo entre a reserva do possível e o mínimo existencial, atribuir exatamente o que seria "devido" a cada indivíduo, em termos de garantias estatais executáveis.

A par dessa noção, Globekner salienta a dimensão social do direito à saúde, pelo qual, por características próprias do cuidado médico e epidemiológico, promover a saúde do indivíduo corresponde a cuidar do coletivo e tratar do coletivo facilita o cuidado do indivíduo isoladamente considerado. Esse entendimento é responsável pelo atual cenário de intensa concorrência público-privada no atendimento médico nacional, cooperando tanto isoladamente quanto em parcerias licitadas e oficializadas. A prestação de serviços de saúde é uma tarefa cuja extensão tem magnitude insuportável a apenas um dos já mencionados setores, cabendo a ambos cooptar, em termos de

(4) FERRAZ JUNIOR, Tércio Sampaio. Introdução ao estudo do direito: técnica, decisão, dominação. São Paulo: Atlas, 2011. p. 328. 
estrutura e recursos, para o atendimento adequado e universal dos sujeitos titulares desse direito.

Meio a essa política sistêmica "dual", o Estado mantém a função de disciplinar as relações jurídicas públicas, entre os cidadãos e o próprio Estado; as contratuais privadas, entre cidadãos e entes particulares de assistência a saúde e, agora, surge também a regência jurídica entre os agentes públicos e privados de atenção sanitária, ambos essenciais para a finalidade pretendida pelo sistema.

Em conclusão, é necessário ressaltar que a alocação dos recursos sanitários escassos é um desafio constante da sociedade contemporânea, devendo levar em conta os diversos aspectos ilustrados pelo texto em diálogo harmônico. À medida que a ciência médica progride, acompanhará a demanda social por novos tratamentos, modernização das estruturas e abrangência da cobertura social do sistema, provocando a constante necessidade de ponderação desse enigma social, de tal sorte que, em países, cujo sistema de saúde encontra-se substancialmente à frente do nosso, ainda há demandas por melhorias. As escolhas do sistema, por tratarem da vida, bem jurídico muito caro ao nosso ordenamento e sociedade, têm a responsabilidade de obter a maior eficiência possível, tornando essa obra, e o estudo que dela resultou, algo de eminente relevância para a formulação de políticas públicas e privadas de saúde.

\section{REFERÊNCIAS}

FERRAZ JUNIOR, Tércio Sampaio. Introdução ao estudo do direito: técnica, decisão, dominação. São Paulo: Atlas, 2011.

FERREIRA FILHO, Manoel Gonçalves. Curso de direito constitucional. 35. ed. São Paulo: Saraiva, 2009.

GLOBEKNER, Osmir Antonio. A saúde entre o público e o privado: o desafio da alocação social dos recursos sanitários escassos. Curitiba: Juruá, 2011.

MONTESQUIEU, Charles Luis de Secondat. O Espírito das leis. Disponível em: <www.file:////Lenin/RedeLocal/Equipe/Michele/MONTESQUIEUOEspíritodasLeis2.txt>. Acesso em: 29. out. 2012.

MORAES, Alexandre de. Direito constitucional. São Paulo: Atlas, 2012. 